\title{
Making Sense of New Orleans Flood Trauma Recovery: Ethics, Research Design, and Policy Considerations for Future Disasters
}

\author{
Michael Robert Dennis*
}

University of Kansas

\section{Adrianne D. Kunkel}

University of Kansas

Gillian Woods

University of Kansas

\section{Paul Schrodt}

Texas Christian University

This article details the justification and plans of a research team for studying and helping evacuees of Hurricane Katrina from New Orleans to recover by encouraging experimental participants to disclose information about their related experiences in guided interview sessions. Team members' consideration and practice of ethical principles as researchers dealing with the potentially traumatized victims of a disaster are portrayed. Finally, related recommendations for researchers and policy makers are offered.

\section{Hurricane Katrina: Watching the Delayed Destruction of "Our" New Orleans}

Though none of the authors is from Louisiana, several of us have tremendous attachment to New Orleans, its people, institutions, and cultural heritage. The

* Correspondence concerning this article should be addressed to Michael Robert Dennis, Department of Communication Studies, 102 Bailey Hall, 1440 Jayhawk Blvd., University of Kansas, Lawrence, KS 66045-7574 [e-mail: mrdennis@ku.edu]. 
first two authors are great lovers of New Orleans, spent graduate school breaks there together, and got engaged and married in the city formed in an elbow of the Mississippi River. Though not immune to the decadence of Bourbon Street, we preferred the shops on Royal Street, galleries of the Warehouse district, streetcars in the Garden District, and observation of the ceremonial "confrontations" of Mardi Gras Indian Chiefs on the streets and fields of low-income neighborhoods. Our annual trips included shows at Le Petit Theatre, patronage of street buskers, conversation with cabbies on the way to some Mid City happening, a walk around the dueling oaks in City Park, visits with the merchants who supplied our wedding, and the cajun pasta at Petunia's, a French Quarter restaurant known for its crepes and kind service. Admittedly, we were somewhat naive tourists who dealt little with "problem of the Big Easy," such as the extreme inequity of its classes, a history of slave trade and at least sporadic corruption in government and law enforcement, a massive Formosan termite infestation, and a vulnerability to flooding brought about by its location and altitude. Yet, the number of "natives" we met there who had once come to "N'awlins" for a visit and stayed permanently impressed us, as did the almost unfailing good nature and joie de vivre of retailers and workers who seemed always to be humming, whistling, or dispensing tips for enjoying our stay.

As professors of communication studies in America's heartland, we were relieved for a day to see that Hurricane Katrina had done her damage in the late summer of 2005 but not to the cataclysmic potential so many of us feared. The next day, our friends from grad school and a recently graduated student of our own emailed their dismay at the doom of New Orleans and consoled us by encouraging our reliance on great memories of the Crescent City. Confused as to what they could be referring to, we raced to the TV network news and online coverage and found, to our horror, that the levees had been breached and that "the city that care forgot" was drowning. The tragic plight of evacuees and those stranded in the city, along with the inadequacy of organized response agencies, was subsequently documented in excruciating real time media coverage for the world to watch and hear.

This article's third author has witnessed the displacement of family members due to hurricanes in other areas of the South. Her parents grieved as their favorite weekend get-away city of New Orleans was devastated. Her beau grew up in Arkansas and Louisiana, including New Orleans, and his friend and band mate lost everything but his life and dog to Hurricane Katrina and the levee breaches. To process their grief, they wrote and recorded songs about Katrina after an evacuation to Ruston, Louisiana. Our fourth author is from Texas and is well aware of the Gulf Coast's propensity for storms and their damage potential like that visited on the Galveston-Houston area at the turn of the previous century. He also lives in Midlothian, Texas, which, as a hospitable host to many New Orleans evacuees, is the planned site of our research.

For empathetic "outsiders" like us, New Orleans has become a city of bittersweet memories; yet, we do not live with the suffering and grief of losing family 
members, friends, pets, homes, livelihoods, independence, and security. We have been able to push the horrific images from our minds and go on with our lives, unlike the citizens of New Orleans and other affected cities, towns, and areas of Louisiana, Mississippi, and Alabama on or near the Gulf Coast. Thousands of people are traumatized, depressed, anxious, feeling forgotten, and unable to tell their stories or make sense of the tragedy that overwhelmed them. Our heartbreak at the tragedy and ensuing desire to help those traumatized and displaced by Katrina does not stem solely from ties to New Orleans, but rather our human need to ease the pain of those who can be helped. Thus, our reaction, watching from afar the tragic socio-environmental consequences of the 2005 hurricane season, was to vow to make our knowledge and skill sets useful for the victims who may now regret having placed their faith in the city and its history of skirting natural disaster.

\section{Researchers Serving New Orleans}

Environmental activists and hazards assessment teams advocate the restoration of swamplands, long a barrier between storm surges and Louisiana towns and cities. Engineers strive for better manmade protection than the levees currently provide. Political scientists and economists study the budget and procedures of federal organizations charged with responding to emergencies and the factors that will determine whether evacuees of New Orleans will return. Psychologists measure cognitive and emotional impacts of the hurricanes on adult and student populations and community psychologists compile factors that both predict and foster emotional recovery. Our colleagues, scholars in political and environmental communication, may help to construct arguments that will direct funds toward preventative measures for the upcoming seasons. Others, experts in risk communication, will surely seek to improve public alert systems and the coordination of response and rescue agencies for future disasters.

For our part, we have formed a research team that will apply what we know about the communicative and psychological aspects of coping with trauma to advance relevant theories and scholarship to inform individual recovery from disaster. Undoubtedly, the trauma imposed on the survivors and evacuees of the New Orleans flooding brought on by Hurricane Katrina has been great. Norris (2005) reviewed 57 studies of disasters (i.e., 35 of hurricanes, 20 of floods, 4 of tornadoes, and 2 of dam collapses) and their impacts on mental health, and found that $74 \%$ of the samples included victims suffering post-traumatic stress and $33 \%$ included depressed individuals. For instance, several researchers examining the survivors of Hurricane Andrew, which struck Florida, Louisiana, and the Bahamas in 1992 and is surpassed in financial damage caused only by Katrina, found that about 1 in 3 survivors suffered from post-traumatic stress (David et al., 1996; Ironson et al., 1997). Gleser, Green, and Winget (1981) reported prevalent sleep disorders among 
the survivors 2 years after over 130 million gallons of slag, mud, and water overcame the dam that had protected Buffalo Creek, West Virginia, in 1972. Solomon and Smith (1994) detected heightened symptoms of depression, phobia, generalized anxiety, and alcohol abuse among rural residents of the St. Louis area affected by the flooding and exposure to chemical dioxins brought about by winter rains and tornadoes in 1982. Though findings also showed that time passage ameliorates negative effects, over half of the measures of threatened mental health in Norris' review of studies were not concluded until more than a year after the disaster.

As humanists, we seek to foster the recovery of those already damaged by Hurricane Katrina and the flooding of New Orleans, and to influence policy makers in beneficial ways. As social scientists, we write here in hopes that our deliberations about the logistics and ethics of studying crisis survivors will inform similar efforts of other researchers. The rest of this article will describe our plan to enact a study of the mechanisms and benefits of trauma disclosure as well as the special considerations we have struggled with in preparing to both study and help New Orleans evacuees.

\section{Our Project: Recovery from Trauma by Way of Disclosure}

The purpose of this article is to portray how investigations of the social impacts of disasters such as Katrina may be best considered, justified, and designed. Our project will apply and extend the research paradigm regarding emotional disclosure and its benefits. Despite overwhelming findings concerning the affective, cognitive, and behavioral advantages of disclosure regarding distressing events, only informed speculation exists about the mechanisms that foster benefits produced by disclosing. This speculation centers on disclosers' expression of otherwise inhibited related emotion(s), production of sense making about upsetting events, positive reappraisal of upsetting events, and problem-focused coping (i.e., consideration of recuperative actions). Also still to be determined is whether the extent of disclosure benefits for survivors of extremely traumatic and collective disasters matches that for individuals distressed by less severe (e.g., career or relationship setbacks) or more idiosyncratic (e.g., family abuse) stressors. Accordingly, we will verify that the established benefits of disclosure and production of trauma-related narrative are also accrued by survivors of a unique catastrophe, one for which an entire major American city was evacuated and its inhabitants at least temporarily relocated, and identify which of the purported mechanisms of recovery are truly evident in disclosers' narratives.

\section{Benefits of Disclosure for the Traumatized}

The contributions of Pennebaker and his colleagues (e.g., Harber \& Pennebaker, 1992; Pennebaker, 1989, 1993a, 1993b, 1997a, 1997b; Pennebaker \& 
Beall, 1986; Pennebaker, Colder, \& Sharp, 1990; Smyth \& Pennebaker, 1999) have shown that distressed individuals experience enhanced health outcomes, emotional adjustment, and behavioral benefits by writing or speaking about their distressful events. In the typical Pennebaker study, participants think, write, or talk (to a tape recorder or "silent confessor") about (a) a stressful or traumatic experience, or (b) a superficial topic (e.g., what the research participant plans to do following the experiment). Participants disclose for 15-20 minutes per day for several consecutive days.

After disclosing about a stressful experience, experimental participants tend to make fewer visits to health centers (e.g., Pennebaker, Barger, \& Tiebout, 1989; Pennebaker \& Francis, 1996; Pennebaker, Kiecolt-Glaser, \& Glaser, 1988) and derive long-term benefits associated with immunity to disease (Booth, Petrie, \& Pennebaker, 1997; Pennebaker et al., 1988; Petrie, Booth, \& Pennebaker, 1998; Petrie, Booth, Pennebaker, Davison, \& Thomas, 1995), heart rate levels (Hughes, Uhlmann, \& Pennebaker, 1994), and lessened negative physical symptoms (e.g., Greenberg \& Stone, 1992; Pennebaker, 1982; Pennebaker \& Beall, 1986). Disclosers also enjoy decreased levels of distress, negative affect, and depression [see Smyth's (1998) meta-analysis] and improve on certain behavioral markers, such as grade point average (e.g., Pennebaker et al., 1990; Pennebaker \& Francis, 1996), re-employment following job loss (e.g., Spera, Burhfeind, \& Pennebaker, 1994), and absenteeism from work (e.g., Francis \& Pennebaker, 1992).

Though Pennebaker and colleagues have confirmed the existence of stages and norms of social interaction and disclosure among individuals impacted by the Loma Prieta earthquake (Pennebaker \& Harber, 1993), the Texas A\&M Bonfire tragedy (Gortner \& Pennebaker, 2003), and the terrorist attacks of September 11, 2001 (Cohn, Mehl, \& Pennebaker, 2004; Mehl \& Pennebaker, 2003), to date, survivors of disasters have not been examined in studies that adopt the classic disclosure study design.

\section{Mechanisms of Beneficial Disclosure}

Pennebaker and Beall (1986) originally posited that disclosure delivered its many benefits by providing a cathartic release from the extensive cognitive and physiological work of emotional inhibition. They maintained that inhibition is a stressor because it leads to ruminative and obsessive thinking, which may cause cumulative and potentially deleterious stress on the body. More recently, other cognitive activities have been nominated as potentially serving the process of recovery by disclosure (Pennebaker, 1997a). Specifically, sense making, positive reappraisal, and problem-focused coping have been theorized as mechanisms other than emotional expression that may explain the advantages of disclosure.

According to Harber and Pennebaker (1992), successful coping with traumatic thoughts and feelings may depend on "emotional assimilation," which entails 
the individual making sense of them, thus rendering them more comprehensible and manageable. The process of putting one's thoughts into a coherent narrative may help make the distressful event more accessible, more understandable, and less foreign (Clark, 1993). Thus, poorly organized and stressing conceptions of disturbing events may become more coherent representations that are easier to set aside (Pennebaker \& Francis, 1996). Also, when pertinent, the assignment of blame for traumatic events may foster sense making.

Alternatively, disclosure may deliver its health-related returns by way of positive reappraisal. Lazarus (1991) maintains that emotional distress originates in the way in which events are evaluated and appraised. Among the "emotion-focused coping" strategies for adjusting to distress is positive reappraisal or the changing, reframing, or restructuring of the meanings of an experience or event so that they are more optimistic and less threatening. As "finding the silver lining" in an upsetting experience may promote a state of mind that allows the distressed to cope with it, positive reappraisal may be the key coping mechanism (Burleson \& Goldsmith, 1998) especially when the distressed person's situation is unlikely to change (Lazarus, 1991).

When the stressor or trauma, its causes, or recurrence are perceived as malleable, however, the "problem-focused coping" (Lazarus, 1991, p. 112) strategy may be most useful. Performing, advocating, or considering "action-centered" responses that may change disturbing circumstances qualify as problem-focused coping. Problem-focused coping eschews the emotional for rational and deliberate problem solving and is reasonably expected to appear within, and cultivate the established benefits of, narrative and disclosure produced by the distressed.

\section{Our Project's Objectives}

Though the mental, emotional, physical, and behavioral benefits of working through trauma by way of linguistic expression appear to be incontrovertible, the extent to which disclosure helps disaster survivors and the extent to which emotional expression, sense making/blame, positive reappraisal, and/or problemfocused coping are responsible for the benefits of disclosure are not yet clear. Accordingly, the planned project, consisting largely of allowing and/or encouraging New Orleans residents to share their Hurricane Katrina stories within interviews, aims to further establish and extend the disclosure paradigm. Specifically, we plan to accomplish four objectives:

1) Deliver the benefits of disclosure to evacuees of New Orleans, who are likely to be experiencing negative psychosocial and physical effects that may worsen into posttraumatic stress without therapeutic intervention.

2) Enhance understanding of what survivors believe to have been critical to their survival and recovery processes by identifying both (a) the experiences, 
thoughts, and feelings about which evacuees choose to disclose during opportunities to produce Hurricane Katrina-related narrative, and (b) the actions and/or messages produced by family members and others that evacuees consider to have been particularly helpful or unhelpful.

3) Extend the establishment of emotional, mental, and physical benefits of such disclosure to the populations of survivors of catastrophes by determining whether immediately after, and 6 weeks later, experimental participants who produced disclosure display significantly more and greater indications of recovery than do control participants who did not disclose.

4) Enrich scholarly comprehension of, and theory regarding, the mechanisms that deliver the benefits of disclosure by identifying the extent to which the theoretical mechanisms (e.g., emotional expression, sense making/blame, positive reappraisal, and problem-focused coping) of beneficial disclosure are evident in initial evacuee disclosures and discovering whether evacuees may be encouraged to produce emotional expression, sense making/blame, positive reappraisal, and problem-focused coping in their disclosure if they do not do so initially.

We expect to determine what sorts of social support messages the victims of disaster perceive themselves to have received and which of these were most advantageous for survival and recovery. We also anticipate that we will provide evidence that emotional disclosure provides a myriad of benefits to surviving evacuees of New Orleans and that we will be in a position to advise its practice by victims and survivors of future similar traumatic disasters. We should also be able to promote particular mechanisms within disclosures that appear to be prevalent and most functional for recovery. In the event that we are not able to conclude that the well-established benefits of disclosure are accrued by our sample, we will have to consider whether to determine the factors responsible for that outcome or to question the wisdom of advising its practice to individuals traumatized by disaster.

\section{Our Project's Methodology}

Almost a year after Hurricane Katrina, our research team is seeking adequate funding. A federal agency that is providing grants to study the aftermath of the hurricanes was not enamored with our application's stated intention of assisting, as well as examining, our eventual participants. We agreed to withdraw our application and seek funding elsewhere rather than betray our initial motivations to serve and study.

The research team members will initially travel to Midlothian, Texas, the site of Camp Hoblitzelle, where many evacuees from the New Orleans area were originally relocated. The Executive Director of the Salvation Army Headquarters 
in Texas has agreed to arrange meetings with evacuees who remain in Midlothian and to provide contact information for those who now reside elsewhere in Texas and Louisiana. We will collect data from 150 volunteer participants.

We will recruit 75 experimental group participants to spend an hour answering questions and producing narrative on 2 consecutive days. They will be compensated $\$ 50$ for each of the 2 treatment days and $\$ 50$ more upon our receipt of the delayed post-test. Seventy-five control group subjects will not be interviewed but will be compensated $\$ 50$ for completing the pretest and the posttest on consecutive days and $\$ 50$ more upon our receipt of the delayed posttest. An informed consent form approved by the University of Kansas's institutional review board will be administered and read to participants. Upon acquiring their signed consent, researchers will provide another copy for their records. On-site data collection will be completed 10-12 weeks after its commencement. Collection of delayed posttests will continue for 6 weeks after the last participant is recruited. On their first day of participation, participants will spend approximately 15 minutes completing a pretest battery of measures [i.e., Background Information Questionnaire, Positive and Negative Affect Scale (Watson, Clark, \& Tellegen, 1988), World Assumptions Scale (Janoff-Bulman, 1989), Beck Depression Inventory (Beck, Steer, \& Brown, 1996), Brief Symptom Inventory 18 (Derogatis, 1983), and the Situation Description Task (Kunkel, 2000)] that indicate their current emotional, mental, and physical states as well as their cognitions regarding Hurricane Katrina, the subsequent flooding of New Orleans, and their related experiences.

Experimental participants will be interviewed for approximately 30 minutes about their Hurricane Katrina experiences. Interviewers will initially ask participants general questions about their experiences (see Appendix A, "Initial Disclosures," questions 1-7). Interviews will be recorded into digital files, downloaded to a database, and transcribed into word processing files. Transcripts will be coded, via thematic analysis (Owen, 1984), for topics that experimental participants choose to disclose about on their own and for actions and messages, and their sources, that experimental participants report to have been helpful or unhelpful. Themes will be considered to emerge when there is recurrence (similar meaning was communicated but different words were used) or repetition (the reiteration of key words and phrases) among responses of different participants. Multiple coders will be employed and discrepancies in coding will be discussed and resolved.

Transcripts will also be coded to identify the theoretical mechanisms of beneficial disclosure evident in initial disclosures. We will use the coding scheme established and published in application to the language found in eulogies (see Kunkel \& Dennis, 2003) and in the discourse of breast cancer support group members (see Kunkel, 2005). Thus, instances of emotional expression (e.g., "I'm afraid of this happening again," "I just sobbed the whole night"), sense making (e.g., "if the levee didn't sink each time they added height, we'd be okay," "part of 
the blame goes to the feds, but I put most of the blame on the state"), positive reappraisal (e.g., "at least I learned from this experience to trust experts' warnings," "leaving the house, even though it's not what you want, it's the best thing you could have done"), and problem-focused coping (e.g., "I decided not to let this change my goals," "I just plan on living as much as I can") will be identified and counted. After initial disclosure, interviewers will determine whether they can inspire discourse that features the identified theoretical mechanisms of disclosure benefits by asking questions that employ plain language rather than the scholarly terminology (see Appendix A, "Prompted Disclosure Mechanisms," questions 1-4).

The second day's session will feature a virtual repeat of the disclosure interview and then the posttest battery of measures, which will match that of the pretest without the Background Information Questionnaire. Participants will also be asked to complete the posttest measures again 6 weeks later (i.e., delayed posttest) and to mail them in a self-addressed stamped envelope to the researchers. To assess whether experimental participants who produced disclosure display significantly more and greater indications of recovery than do control participants who do not produce disclosure, the responses to pretest, posttest, and delayed posttest measures will be compiled into a longitudinal data file and analyzed with repeated measures and/or multivariate analyses of variance procedures. This should produce indications of recovery across time and show any differences in recovery between experimental and control group participants.

\section{Ethical Considerations in Our Research Design}

The ethical treatment of research subjects or participants must be privileged in the consideration of all biomedical and behavioral research designs, especially for investigations of victims of disaster. In order to contextualize the description of our responses to ethical issues and our advice for other researchers who study the impacts and victims of disaster, we first revisit the basic ethical principles for conducting research on human beings.

\section{Principles}

In the late 1970s, the 11-member National Commission for the Protection of Human Subjects of Biomedical and Behavioral Research, formed in 1974 within the Department of Health, Education, and Welfare's National Research Act, developed guidelines for the conduct of research with human subjects. The result of 4 years of deliberations that began at the Smithsonian Institution's Belmont Conference Center, the Belmont Report (1978), was published in the Federal Register and still serves today as a framework for the consideration of ethical treatment of research participants. The Belmont Report begins by distinguishing research (i.e., an activity designed in a formal protocol to produce conclusions and contributions 
to general knowledge) and the practice of accepted therapy (i.e., interventions designed and expected to enhance individual well-being).

The Report then sets forth the basic ethical principles for research of respect, beneficence, and justice. Respect for persons entails treating them as autonomous (i.e., accepting their informed judgments and freedom to act on them) or providing them protection if they have diminished autonomy (i.e., illness, disability, lack of maturity) so that human subjects participate in research only voluntarily and in an informed manner. Beneficence is defined as affording subjects a positive balance of benefits relative to potential harms or as efforts to minimize risks and magnitudes of harms while maximizing benefits. Justice pertains to the distribution of benefits and burdens of research. The principle of justice is violated, for example, if only upper social class members of a society benefit from therapies whose testing and development put at risk solely lower social class members.

Finally, the Belmont Report regards the application of the ethical principles in terms of informed consent, assessment of risks and benefits, and the selection of subjects for research. Informed consent allows research subjects to choose what will happen to them, at least in regard to whether they participate in research or not, and to do so with sufficient relevant information. This information should include the purpose of the research and its procedures, risks and benefits, and opportunities for subjects to ask questions and to withdraw from research at any time they choose to. Information should be delivered in formats that are adapted to and easily accessible for subjects to comprehend. Information should be withheld only if its exposure threatens the validity of the research and, even then, should be revealed as soon as possible. Consent to participate must thus be well informed and voluntary rather than coerced or the result of undue influence such as excessive or inappropriate inducement to comply.

The assessment of risks and benefits must include analysis of all relevant data including information about alternative ways of obtaining the intended research benefits. Risk and harm are noted for their characteristic qualities as evaluations of both the probability and magnitude of severity. Therefore both probability and magnitude of harms should be considered. Harms of all kinds (e.g., physical, psychological, economic, legal, social) should be assessed, as should their potential levels of affect (e.g., to individuals, families, society). Risks of harm should be minimized and both harms and the involvement of populations especially vulnerable to them should be justified.

The selection of subjects should be governed by fair procedures and marked by fair outcomes. Researchers must practice individual justice and fairness by not offering potentially beneficial research only to favored individuals or subjecting only less favored persons to risk. Researchers must practice social justice by distinguishing among subjects who should or should not participate based on their capacities to bear burdens. Special care must be taken not to rely on burdened subjects (e.g., the impoverished, the institutionalized) who are too easily accessed. 


\section{Practice}

We first determined that though our study offers an accepted therapy intervention expected to enhance individual well-being, its primary purpose was to evaluate the effectiveness of the disclosure intervention on the particular population of interest (i.e., survivors and evacuees of the New Orleans flood brought about by Hurricane Katrina) and to draw conclusions about the contents of their initial and prompted disclosure. Because the Belmont Report suggests that any activity that includes any element of research be reviewed in order to protect human subjects, we examined our study for characteristics of respect, beneficence, and justice.

Respect and informed consent. Given the nature of trauma that may have been suffered by New Orleans evacuees and the exclusion of children from other disclosure studies, we decided that individuals under the age of 21 had diminished autonomy to decide for themselves in an informed manner and excluded their participation from our study. For those we regarded to be autonomous, we constructed an informed consent form that notes potential benefits and risks to them and assures that participation will be both confidential and voluntary. The form was approved by our University's institutional review board and written in a manner that revealed the procedures but only to a level of detail that maximized the probability of comprehension by participants. The form tells participants that the purpose of the research regards "the benefits of talking about distressing events and the reasons that those benefits exist" and describes the procedures as asking participants "to respond to a series of questionnaires on 2 consecutive days and again once 6 weeks later" and that "some participants will also be asked to talk about their Hurricane Katrina-related experience(s) on 2 consecutive days." It also advises that "participation in this study should take 60 minutes or less for each of up to three sessions," that "neither participants' names nor other identifying information will be collected ... confidentiality is assured" and that "you do not have to participate in this research project. If you do agree to participate, you can withdraw your participation at any time without penalty." Both risks and benefits to the individual are detailed in accordance with the assessments described in the next section. Included are that "participants may be at minimal risk, as they will be asked to describe their Hurricane Katrina and New Orleans flooding experiences as well as their related and current thoughts and feelings" and that "there are no right or wrong answers in the study." Moreover, the form states "it is anticipated that the emotional, physical, and mental recovery of individual experimental participants from the stress and/or trauma of Hurricane Katrina may be fostered" and that "participants may also earn $\$ 50$ per hour of participation for a maximum of 3 hours (i.e., \$150)." Finally, participants are given names and contact information for the first two authors and the institutional review board and advised to "ask 
questions about the research project" before acknowledging that they are over 21 years old and signing their consent.

The research team desired to offer incentives to not only commence but also to complete participation, which entailed sessions on 2 consecutive days and the completion of a delayed posttest 6 weeks after the second day. We also wanted to respect the balance between compensating participants well for their efforts and time as they continue to rebuild their lives and concerns about unduly influencing them to comply with excessive or inappropriate inducements. We arrived at $\$ 150$ as a motivating but not necessarily compelling total incentive and believe that offering it in stages (i.e., \$50 for each of the first and second day's sessions and for the completion of the final battery of measures 6 weeks later) was appropriate and allowed for the fair compensation of participants who choose to withdraw from the study at any time.

Beneficence and assessment of risks and benefits. Asking participants to reconsider what were likely to have been the worst days of their lives mandates identification of the severity and likelihood of harms that might be induced. Pennebaker (1997a) and others have affirmed that experimental participants in disclosure studies often feel worse immediately after sessions than before them. Moreover, Herbert et al. (2001) worry that the "debriefing programs" offered by crisis intervention companies to groups of New York corporate employees after the September 11th terrorist attacks actually impeded their emotional recovery, perhaps by exposing participants to the disturbing memories of others and to experts' anticipation of mental and emotional problems they would encounter (Smith, 2005). Clearly, our study may introduce opportunities for hurtful rumination about experienced traumas or other iatrogenic effects as disclosers could become overwrought or distressed by their revisiting of personal trauma. Nonetheless, the series of disclosure studies have incontrovertibly shown that these potential risks to subjects are minimal and similar to those associated with any form of psychotherapy. Physical, social, and legal consequences are not expected to occur. Increases in levels of overall distress, anxiety, and depressive symptomology are expected to occur rarely and to dissipate soon after disclosure sessions. It would be entirely unexpected for the planned research intervention to cause long-term psychological distress.

Despite the low probability of harms, we were obliged to act to minimize as much as possible their likelihood and severity. We determined that our participants would disclose individually rather than interact with other participants. This procedure serves both to ward off the potentially deleterious effects of group disclosure and debriefing sessions (Herbert et al., 2001; Smith, 2005) and to assure confidentiality, so that participants bear no risk of damage to reputation or social standing brought about by others in their community learning about their actions during the disaster, concerns and feelings, or any perceived weaknesses in character. We fur- 
ther minimize risk of harm by varying from the standard disclosure study design of having participants disclose privately as well as individually. We were concerned about leaving disaster survivors alone to recall and deal with their trauma. Instead, one researcher will guide participants through a structured interview intended to elicit disclosure. Thus, participants may be constantly monitored for signs of duress. In fact, a Master's-level psychologist with a temporary Kansas state license is on the research team and will be available during the research sessions to assess participants' needs beyond that of the therapeutic intervention. Any participants who illustrate clinical levels of psychological and psychosomatic distress and/or those who present with symptoms in need of crisis intervention (e.g., suicidal ideation), would be immediately connected with on-site or area mental health care professionals. The research team will debrief both the experimental and control group participants about any potential psychological and psychosomatic changes due to trauma, and subjects will be provided with contact information for area health care professionals.

Beyond minimizing the probability and severity of harms, we were compelled to identify and maximize the likelihood and magnitude of benefits to participation. Of course, on the social level, we expect to provide determination of whether and how victims of intensely negative and life-changing events, such as disaster, acquire the benefits of disclosure. On the individual level, we are confident that the study will foster long-term recovery for our participants far more than it will deliver immediate distress. Fortunately, the preponderance of evidence for studies of less traumatized samples supports our confidence. The negative psychological symptoms, both due to the traumatic experiences and the discussion and evaluation of such experiences, are expected to decrease after the continued cognitive appraisal and restructuring of participants' thoughts, emotions, and ensuing behavioral responses to their hurricane experiences. Extant disclosure research indicates that subjects continue the rational-emotive, narrative, and behavioral therapy processes after the conclusion of the direct intervention. Such appraisal and evaluation of one's thoughts and feelings associated with distressing experiences have led to significantly improved delayed posttest and follow-up psychological and physiological functioning (e.g., Esterling, Antoni, Fletcher, Margulies, \& Schneiderman, 1994; Harber \& Pennebaker, 1992; Pennebaker, 1989, 1993a, 1993b, 1997a, 1997b; Pennebaker \& Beall, 1986; Pennebaker et al., 1990; Smyth \& Pennebaker, 1999). Moreover, the intervention is expected to prevent the development of post-traumatic stress symptoms related to the traumatic hurricane and flooding experiences.

To assure the acquisition of these benefits to individuals, we will attempt to inspire emotional expression, sense making/blame, positive reappraisal, and problem-focused coping by experimental group participants who do not produce these theorized mechanisms of disclosure's benefits on their own (see both the "Initial Disclosures" and "Prompted Disclosure Mechanisms" sections of the 
Disclosure Interview Schedule in Appendix A). Though we cannot both preserve internal validity of our design and provide the benefits of disclosure to control group participants, we will encourage and facilitate the tracking of our progress and results by all participants in hopes that they will be prompted to adopt the practice of beneficial disclosure in the future.

Finally, to secure the benefits to science and society, the competence and qualification of the researchers to perform the collection and interpretation of the particular sort of data the study will generate should be verified. If we were not capable of performing a disclosure study adequately, the appropriate balance of benefits to potential harms would be upset. Kunkel (2000), the second author of this article, examined whether: (a) distress disclosure addressed as though for another person has more beneficial outcomes than when it is constructed solely for oneself, (b) distress disclosure has more beneficial outcomes when delivered through a written as opposed to an oral communication modality, and (c) distress disclosure has more beneficial outcomes when accompanied by opportunities to review and reflect upon the disclosure text than when not accompanied by such opportunities. Over 200 undergraduate students completed a battery of pretest measures and then were assigned to either one of eight experimental conditions comprising combinations of the three dichotomous independent variables (talk vs. write; address disclosure at another or for oneself; reflect vs. not) or a control group that focused on a trivial topic instead of a stressor. Experimental subjects were instructed to disclose for approximately 20 minutes about a problem in their lives and all participants performed their respective writing or talking tasks for 4 consecutive days. On the fourth day, participants were asked to fill out immediate posttest scales. Kunkel found few significant differences among the dependent variables and across levels of the independent variables and concluded that disclosure in all tested formats fostered approximately equivalent levels of improvement and recovery.

Moreover, the first two authors examined contemporary eulogies (Kunkel \& Dennis, 2003; Dennis \& Kunkel, 2004) and demonstrated the ability to identify and explain instances of emotional expression (e.g., " ... it is so cold and sad for us, " "Oh, the anger I feel! .. I I will face the demons of sorrow and grief"), positive reappraisal (e.g., "I know that when you reached the gates of Heaven, there wasn't any hesitation on the part of Saint Peter," "And for a thousand days, he was a husband who adored the wife who became his perfect soul mate"), and problemfocused coping (e.g., "I want to stress to everyone here that no one should feel guilt ... Let us each instead vow to use our energy to help each other and ourselves. Let that be our tribute to Trevor," "Get back on the airplanes! Go back to work! Rebuild America!”).

Justice and selection of subjects. The project draws its participants as a proportionately representative sample of the affected population. Aware that the hurricane negatively affected members of various sexes, ethnicities, and religions, we 
resolved that women and minorities would be fairly included as participants so as to maximize the scope of generalizability of our results and thus also the range of people whose recovery might be best enhanced in the future. Though individuals of lower economic standing can be argued to have been subject to the most extreme trauma during the period immediately following the flooding, as they were most likely to both live in underlying and vulnerable areas of New Orleans and to have lacked the means to evacuate before the levees failed, all citizens of the city suffered various losses and traumas. We believe that members of all economically determined categories are roughly equal in likelihood to have passed through Midlothian during their evacuation and/or relocation and that all classes will be represented.

Considerations of justice in research design also oblige fair distribution of both its benefits and burdens among disparate individuals. One way of ensuring justice then is to decrease the burdens on research participants. We thus chose to deviate from the standard schedule of participants disclosing about their distressing situations for 4 consecutive days and opted for just 2 consecutive days of disclosure interview sessions. It is one thing to ask college students to report for research participation between their Western Civilization and Biology classes for 4 straight days and quite another to solicit such a commitment from people trying to reconstruct their disrupted lives. This modification seems fair, though it introduces the potential for a confounding variable between our study and past investigations of less traumatized participants. In a similar concession, our research team agreed that invoking the effort required to produce written narratives was more than we could reasonably ask of participants who had so much else to deal with on a daily basis. Thus, oral disclosure was adopted as the mode for all experimental participants. Oral disclosure also seems reasonable for general population research in which some respondents may not be comfortable or highly skilled at expressing themselves in writing.

Another way to ensure justice and fair distribution is to remember that even if, as expected, participants benefit physically, mentally, and/or emotionally from their opportunities to disclose, this will be no panacea for the problems they have inherited as survivors of disaster. Many of them may remain essentially homeless and unemployed and face very difficult economic and readjustment periods that no amount of effective counseling will negate. We have resolved, even as we expect to help, not to dismiss participants as though they were fully recovered when they complete the project. Concern for their futures must remain in our thoughts and should be expressed during and after the conclusion of sessions, along with our vast gratitude for their willingness to further our cause of understanding.

\section{Recommendations for Researchers}

Throughout the process of researching the literature and context of disasters and their victims in general and the devastation of New Orleans by Katrina in 
particular, our team reflected on advice we could offer other researchers as well as on how to design our own investigation. Foremost in our considerations is emphasis of the opportunity that these horrible circumstances have provided for research that may make a tremendous difference for society as well as affected individuals. John Logan, a sociology professor at Brown University investigating the impacts of Katrina on race and class levels, may have stated it best when he "called the magnitude of displacement a "once-in-a-century-event"" and noted researchers" "moral and social obligation" to study it ("Hurricane Katrina: Who Was Hit?", 2006). Though there are certainly plenty of relevant studies to be performed by natural scientists such as meteorologists and the biologists funded by the National Oceanic and Atmospheric Administration-an agency of the U.S. Commerce Department, to examine effects of Katrina on marine life, fisheries, and the ecosystem - we believe there is an imperative for social scientists to get similarly involved. For instance, with National Science Foundation funding ("NSF announces new awards," 2005), William Wallace of the Rensselaer Polytechnic Institute and Bryan Jones of the University of Washington are investigating the performance of the Federal Emergency Management Agency and the U.S. Coast Guard in responding to the Katrina crisis and the role of their budgets and customary procedures, while Nina Lam of Louisiana State University leads a team exploring the decision making process of businesses regarding their possible return to the New Orleans area.

Though our team combines communication professors with different specialties (i.e., heath communication, social support and interpersonal relationships, and family communication) and a gerontology/psychology student interested in communication and mental health, more far-ranging efforts to produce interdisciplinary social research are possible. Logan's research team includes professors of sociology, environmental studies and geological sciences analyzing public health, environmental hazards, and natural protection from hurricanes.

We can imagine other issues that may be researched in the post-Katrina ruins and rebuilding, though we are not aware of relevant efforts that may be underway. For instance, given the prevalence of potentially deleterious mental health conditions (e.g., post-traumatic stress, depression, anxiety, suicidal ideation) shown to arise as the result of past disasters, mental health researchers should be assessing the extent of their prevalence in the New Orleans area. As the literature regarding disaster trauma and recovery has identified factors that foster recovery and mental stability (e.g., self-efficacy, self esteem, hope, optimism, perceived availability of social support; see Norris, 2005 for a review), researchers should investigate both how prevalent these characteristics are among survivors and the conditions that promote them. Researchers should also strive to identify the variables of disaster warning and communication processes that were in place and the demographic (e.g., socioeconomic status) and psychographic (e.g., worldview, religiosity) characteristics (see Perry \& Mushkatel, 1986, for a treatment of idiosyncratic reactions 
to disaster and warnings of American ethnic groups and minorities) that explain the failure of many New Orleans citizens to evacuate before it was too late to guarantee their survival.

Our own struggles with design lead us to recommend flexibility and creativity on the part of researchers who head to the sites of disaster. A pronounced source of concern for us as we attempted to locate participants was that they had been scattered by the nearly unprecedented temporary loss of an entire major city. Though we knew almost instantly that great numbers of evacuees would be located at particular sites (e.g., the Superdome in New Orleans, the Astrodome in Houston, the Cajun Dome in Baton Rouge), it was difficult to discern how long each site would remain a host. It was also challenging to determine what officials or agencies would be empowered with the ability to grant us access to the evacuees and even more difficult to decide whether we should be distracting such parties with our requests for access. Therefore, we were thankful to locate the Executive Director of the Salvation Army Divisional Headquarters in Texas and secure his permission to meet New Orleans evacuees that the Salvation Army had relocated or served in any manner at Camp Hoblitzelle in Midlothian. Other variations from the standard disclosure investigation design were necessitated by the logistic realities of studying a displaced population. Somewhat swiftly, a good number of the evacuees once in Midlothian were relocated to places like Baton Rouge and Thibodaux in Louisiana, and to Dallas, Houston, San Antonio, and Galveston in Texas. We thus decided to schedule ten different trips from Kansas to recruit participants and collect data. Specifically, we settled on the plan to collect data from 10 experimental group participants on each of five 5-day (Sunday night to Friday) visits and from 5 experimental group and 15 control group participants on each of five 4-day (Thursday night to Monday) visits to reach our goal of 75 experimental and 75 group participants. The proportion of those trips that will be to Midlothian as opposed to other sites of relocation is still to be determined.

We also advise our fellow researchers to consider the course they may be setting for researchers of future disasters. It is critical to continuously reflect upon both the replicability of designs and generalizability of results. Projects should be constructed so that colleagues can repeat them with other samples of victims of hurricanes or future disasters or compare them fairly to populations that have not been beset by disaster. Of course, we also implore researchers to devote effort to not just meeting the requirements of pertinent institutional review boards, but to upholding the standards of the Belmont Report regarding respect, beneficence, and justice.

We close this section with a final ethical dilemma idiosyncratic (we hope) to the case of New Orleans, Hurricane Katrina, and the flooding of the city, that we ultimately chose to address by doing nothing. As concerned and compassionate citizens of this country, we were dismayed by the protection and rescue operations of entities charged with those duties. From the levees built to lower than category 
5 hurricane sustaining standards to the "MR. GO" (Mississippi River Gulf Outlet) canal that prioritized commerce over safety and created a direct route to the city for hurricanes to blow through, to federal agencies and their weak claims that they had not been given the go ahead to act by local and regional authorities, to politicians and voters who continued for years to ignore the problems of swamp erosion and environmental change, there is plenty of blame to go around. Indeed, assessments of whether victims and observers of disasters attempt to attribute blame to aircraft inspectors for airline accidents (Bucher, 1957), builders for faulty construction destroyed by tornadoes (Perry \& Perry, 1959), and flood victims for locating their homes close to sources of inundation (Walster, 1966) have shown that they do. In a study of residents of Catahoula Parish, a flood-prone area of Louisiana, Simpson-Housley and de Man (1987) found that women will attribute more blame to potentially culpable individuals as the severity of a disaster increases and that blame responses vary from disaster to disaster. Armed with the rationale that sense making, and even blaming, can be an important aspect of the recovery by disclosure process, we were tempted to nominate, within the Prompted Disclosure Mechanisms section of our interview sessions, the specific sources of inadequate, if not inept, action regarding Katrina, the flooding, and the stranding of so many residents. We decided instead to leave the questions regarding sense making, causes, and blame open-ended so that participants could decide for themselves whether to vent their frustrations with particular parties, to focus on natural causes, or to refrain from "the blame game" altogether.

\section{Recommendations for Policy Makers}

We have also contemplated what we would tell those in the position of creating or modifying social and legal policy should they inquire after whatever wisdom our deliberations have provided. Some of our suggestions pertain more to our research activities and considerations than do others. To facilitate improved future preparation, we first echo the sentiments of Lee Clarke, a sociologist at Rutgers University. Clarke (2005) wrote that we need leaders that have the vision to imagine and prepare for worst-case storm scenarios rather than just the most likely ones, the power to allocate resources accordingly, and the conviction to put individuals' well-being above the priorities of bureaucratic government. As communication scholars, we recognize not just the importance of such leadership but also the seemingly obvious but rarely accomplished mastery of organizational communication between levels of government. A clearly enunciated system of responsibilities that depends on precise distribution of powers and communication of circumstances that trigger them is essential to the survival of future disasters.

In light of the failure to produce adequate leadership or communication, we assume that preparedness would be best served by either the replacement or the vast improvement in performance of the governing individuals that oversaw the responses to Katrina. One mode of improvement might be to enact what our re- 
search represents at the level of governing officials. As politicians and government leaders have the potential to either mitigate or exacerbate the impact disaster has on the citizens they represent, how they make sense of, interpret, and reframe disaster has serious implications for how victims experience it. That is, if officials mediate the relationship between nature and individuals, examining by way of disclosure how they process, respond, and empathize with the victims' experiences of the traumas may inform them and future politicians and government officials. Convincing leaders to reflect on their meaning-making systems and emotions may lead them to better understand how their own rhetoric and performances affect their constituents and may have a profound influence on how their performance is evaluated in public opinion.

Our review of the mental health and disaster literature uncovered the critical nature of instilling perceptions of efficacy, control, esteem, and hope, among individuals who have been traumatized. If those in charge of coordinating protection, evacuation, rescue, and recovery efforts can develop modes for accomplishing these functions that inspire positivity and give those served a role in helping themselves and others in their communities, the collateral damage to mental health is likely to be far less than it would be otherwise. Allowing victims to have a voice and to take action in the immediate aftermath and the later rebuilding processes may restore the confidence and optimism that are so severely shaken by tragedy.

We believe that two sectors of the population that bore the brunt of the suffering in the crises of Katrina have been relegated to the background by the deserved attention on the unfair treatment of minorities and those of low socioeconomic status in New Orleans. We urge extra consideration to the plight of the elderly and those diagnosed and/or institutionalized with mental illness. Before the hurricane, these groups were already underprivileged, as our culture largely shuns those dealing with disability and the latter phases of life. People who were incapacitated in nursing homes or in hospitals of all types died for the complete lack of a plan for their evacuation. Moreover, many children in lower SES families may have lost their primary caregiver grandparents and will end up in foster care, an often less than desirable institution. We also know that the disaster will have caused many other individuals to develop mental health problems. Though resources for these populations are limited in American society and this shortfall will be magnified in the new New Orleans, every dollar spent for any mode of prevention or treatment of the physical and mental health symptoms resulting from trauma due to natural disasters should save the recovering government a fortune in the long term.

Our research team will soon enact the plans described herein for studying the role that guided disclosure can play in recovery processes. Our future publications will portray the extent to which we delivered the benefits of disclosure to evacuees of New Orleans, extended the establishment of emotional, mental, and physical benefits of such disclosure to the populations of survivors of catastrophes, and enriched scholarly comprehension of the mechanisms that deliver the benefits of disclosure. We hope that our considerations of ethics, appropriate research design, 
and public policy may inform the efforts of those considering serving and/or investigating populations that have been stricken by disasters of great magnitude.

\section{References}

Beck, A. T., Steer, R. A., \& Brown, G. K. (1996). Beck Depression Inventory Manual (2nd ed.). San Antonio, TX: The Psychological Corporation.

The Belmont Report: Ethical principles and guidelines for the protection of human subjects of research. (1978). Department of Health, Education, and Welfare Publication No. (OS) 78-0012.

Booth, R. J., Petrie, K. J., \& Pennebaker, J. W. (1997). Changes in circulating lymphocyte numbers following emotional disclosure: Evidence of buffering? Stress Medicine, 13, 23-29.

Bucher, R. (1957). Blame and hostility in disaster. American Journal of Sociology, 62, 467-475.

Burleson, B. R., \& Goldsmith, D. J. (1998). How the comforting process works: Alleviating emotional distress through conversationally induced reappraisals. In P. A. Anderson \& L. K. Guerrero (Eds.), Communication and emotion: Theory, research, and applications (pp. 245-280). Orlando, FL: Academic Press.

Clark, L. F. (1993). Stress and the cognitive-conversational benefits of social interaction. Journal of Social and Clinical Psychology, 12, 25-55.

Clarke, L. (2005). "Worst case Katrina" [Electronic version]. (2005, September 12). Understanding Katrina: Perspectives from the social sciences. Retrieved May 28, 2006 from http:// understandingkatrina.ssrc.org/Clarke

Cohn, M. A., Mehl, M. R., \& Pennebaker, J. W. (2004). Linguistic markers of psychological change surrounding September 11, 2001. Psychological Science, 15, 687-693.

David, D., Mellman, T., Mendoza, L., Kulick-Bell, R., Ironson, G., \& Schneiderman, N. (1996). Psychiatric morbidity following Hurricane Andrew. Journal of Traumatic Stress, 9, 607612 .

Dennis, M. R., \& Kunkel, A. D. (2004). Fallen heroes, lifted hearts: Consolation in contemporary Presidential eulogia. Death Studies, 28, 703-731.

Derogatis, L. R. (1983). The Brief Symptom Inventory 18: Administration, scoring, and procedures manual. Towson, MD: Clinical Psychometric Research.

Esterling, B. A., Antoni, M. H., Fletcher, M. A., Margulies, S., \& Schneiderman, N. (1994). Emotional disclosure through writing or speaking modulates latent Epstein-Barr virus antibody titers. Journal of Consulting and Clinical Psychology, 62, 130-140.

Francis, M. E., \& Pennebaker, J. W. (1992). Putting stress into words: The impact of writing on physiological, absentee, and self-reported emotional well-being measures. American Journal of Health Promotion, 6, 280-287.

Gleser, G. C., Green, B. L., \& Winget, C. (1981). Prolonged psychosocial effects of disaster: A study of Buffalo Creek. New York: Academic Press.

Gortner, E.-M., \& Pennebaker, J. W. (2003). The archival anatomy of a disaster: Media coverage and community-wide health effects of the Texas A\&M bonfire tragedy. Journal of Social and Clinical Psychology, 22, 580-603.

Greenberg, M. A., \& Stone, D. A. (1992). Emotional disclosure about traumas and its relation to health: Effects of previous disclosure and trauma severity. Journal of Personality and Social Psychology, 63, 75-84.

Harber, K. D., \& Pennebaker, J. W. (1992). Overcoming traumatic memories. In S. A. Christianson (Ed.), The handbook of emotion and memory: Research and theory (pp. 359-387). Hillsdale, NJ: Erlbaum.

Herbert, J. D., Lilienfeld, S., Kline, J., Montgomery, R., Lohr, J., Brandsma, L., Meadows, E., Jacobs, W. J., Goldstein, N., Gist, R., McNally, R. J., Acierno, R., Harris, M., Devilly, G. J., Bryant, R., Eisman, H. D., Kleinknecht, R., Rosen, G. M., \& Foa, E. (2001, November). Primum non nocere [Open letter]. APA Monitor on Psychology, 32(10). Retrieved August 26, 2006, from http://www.apa.org/monitor/nov01/letters.html.

Hughes, C. F., Uhlmann, C., \& Pennebaker, J. W. (1994). The body's response to processing emotional trauma: Linking verbal text with autonomic activity. Journal of Personality, 62, 565-585. 
"Hurricane Katrina: Who was hit? Who will return?" [Electronic version]. (2006, February 10). Inside Brown: News, people and ideas at the University. Retrieved May 28, 2006 from http://www. brown.edu/Administration/InsideBrown/2006/021006d.html

Ironson, G., Wynings, C., Schneiderman, N., Baum, A., Rodriquez, M., Greenwood, D., Benight, C., Antoni, M. H., LaPerriere, A., Huang, H., Klimas, N., \& Fletcher, M.A. (1997). Posttraumatic stress symptoms, intrusive thoughts, loss, and immune function after Hurricane Andrew. Psychosomatic Medicine, 59, 128-141.

Janoff-Bulman, R. (1989). Assumptive worlds and the stress of traumatic events: Applications of the schema construct. Social Cognition, 7, 113-136.

Kunkel, A. W. (2000). Coping with emotional distress: Effects of disclosure mode on cognitive, affective, and health outcomes. Unpublished doctoral dissertation, Purdue University, West Lafayette, Indiana.

Kunkel, A. (2005). Understanding the efficacy of a breast cancer support group from an appraisal and coping perspective. Paper presented at the Central States Communication Association, Kansas City.

Kunkel, A. D., \& Dennis, M. R. (2003). Grief consolation in eulogy rhetoric: An integrative framework. Death Studies, 27, 1-38.

Lazarus, R. S. (1991). Emotion and adaptation. New York: Oxford University Press.

Mehl, M. R., \& Pennebaker, J. W. (2003). The social dynamics of a cultural upheaval: Social interactions surrounding September 11, 2001. Psychological Science, 14, 579-585.

"NSF announces new awards" [Electronic version]. (2005, December 28). National Science Foundation: Where discoveries begin. Retrieved May 28, 2006 from http://www.nsf.gov/news/news. summ.jsp?cntn_id=105650

Norris, F. (2005). Range, magnitude, and duration of the effects of disasters on mental health: Review update 2005. Research education disaster mental health [Electronic version]. Retrieved May 28, 2006 from http://www.redmh.org.research/general/effects.html

Owen, W. F. (1984). Interpretive themes in relational communication. Quarterly Journal of Speech, 70, 274-287.

Pennebaker, J. W. (1982). The psychology of physical symptoms. New York: Springer-Verlag.

Pennebaker, J. W. (1989). Confession, inhibition, and disease. In L. Berkowitz (Ed.), Advances in experimental social psychology (Vol. 22, pp. 211-244). New York: Academic Press.

Pennebaker, J. W. (1993a). Overcoming inhibition: Rethinking the roles of personality, cognition and social behaviors. In H. C. Traue \& J. W. Pennebaker (Eds.), Emotion, inhibition, and health (pp. 100-115). Toronto, Canada: Hogrefe \& Huber.

Pennebaker, J. W. (1993b). Putting stress into words: Health, linguistic, and therapeutic implications. Behavioral Research and Therapy, 31, 539-548.

Pennebaker, J. W. (1997a). Opening up: The healing power of expressing emotions (rev ed.). New York: Guilford.

Pennebaker, J. W. (1997b). Writing about emotional experiences as a therapeutic process. Psychological Science, 8, 162-166.

Pennebaker, J. W., Barger, S. D., \& Tiebout, J. (1989). Disclosure of traumas and health among holocaust survivors. Psychosomatic Medicine, 51, 577-589.

Pennebaker, J. W., \& Beall, S. K. (1986). Confronting a traumatic event: Toward an understanding of inhibition and disease. Journal of Abnormal Psychology, 95, 274-281.

Pennebaker, J. W., Colder, M., \& Sharp, L. K. (1990). Accelerating the coping process. Journal of Personality and Social Psychology, 58, 528-537.

Pennebaker, J. W., \& Francis, M. E. (1996). Cognitive, emotional, and language processes in disclosure. Cognition and Emotion, 10, 601-626.

Pennebaker, J. W., \& Harber, K. D. (1993). A social stage model of collective coping: The Loma Prieta earthquake and the Persian Gulf War. Journal of Social Issues, 49, 125-145.

Pennebaker, J. W., Kiecolt-Glaser, J., \& Glaser, R. (1988). Disclosure of traumas and immune function: Health implications for psychotherapy. Journal of Consulting and Clinical Psychology, 56, 239-245

Perry, R. W., \& Mushkatel, A. H. (1986). Minority citizens in disasters. London: The University of Georgia Press. 
Perry, H. S., \& Perry, S. E. (1959). The schoolhouse disasters: Family and community as determinants of the child's response to disasters. Washington, DC: National Academy of Sciences.

Petrie, K. J., Booth, R. J., \& Pennebaker, J. W. (1998). The immunological effects of thought suppression. Journal of Personality and Social Psychology, 75, 1264-1272.

Petrie, K. J., Booth, R. J., Pennebaker, J. W., Davison, K. P., \& Thomas, M. G. (1995). Disclosure of trauma and immune response to a hepatitis B vaccination program. Journal of Consulting \& Clinical Psychology, 63, 787-792.

Simpson-Housley, P., \& de Man, A. F. (1987). The psychology of geographical disasters. Ontario: Geographical Monographs.

Smith, S. (2005). Trauma and the brain: Outsourcing compassion. American Radio Works, available http://americanradioworks.publicradio.org/features/ptsd/compassion-script1.html

Smyth, J. M. (1998). Written emotional expression: Effect sizes, outcome types, and moderating variables. Journal of Consulting and Clinical Psychology, 66, 174-184.

Smyth, J. M., \& Pennebaker, J. W. (1999). Sharing one's story: Translating emotional experiences into words as a coping tool. In C. R. Snyder (Ed.), Coping: The psychology of what works (pp. 70-89). New York: Oxford University Press.

Solomon, S. D., \& Smith, E. M. (1994). Social support and perceived control as moderators of responses to dioxin and flood exposure. In R. J. Ursano, B. G. McCaughey, \& C. S. Fullerton (Eds.), Individual and community responses to trauma and disaster: The structure of human chaos (pp. 179-200). New York: Cambridge University Press.

Spera, S. P., Burhfeind, E. D., \& Pennebaker, J. W. (1994). Expressive writing and coping with job loss. Academy of Management Journal, 37, 722-733.

Watson, D., Clark, L. A., \& Tellegen, A. (1988). Development and validation of brief measures of positive and negative affect: The PANAS Scales. Journal of Personality and Social Psychology, 54, 1063-1070.

Walster, E. (1966). Assignment of responsibility for an accident. Journal of Personality and Social Psychology, 3, 73-79.

MICHAEL ROBERT DENNIS (PhD, Purdue University, 2001) is an assistant professor in the Department of Communication Studies at the University of Kansas.

ADRIANNE D. KUNKEL (PhD, Purdue University, 2000) is an associate professor in the Department of Communication Studies at the University of Kansas.

GILLIAN WOODS is a doctoral candidate in the Gerontology Program at the University of Kansas.

PAUL SCHRODT (PhD, Purdue University, 2002) is an assistant professor in the Department of Communication Studies at Texas Christian University.

\section{Appendix A: Disclosure Interview Schedule}

\section{Initial Disclosures}

1. Please tell me what has happened to you since Hurricane Katrina approached New Orleans.

2. What are some of the thoughts you have had during these experiences? 
3. What are some of the feelings you have had during these experiences?

4. What, if anything, did your family members or others do that you found to be especially helpful?

5. What, if anything, did your family members or others do that you found to be especially unhelpful?

6. What, if anything, did your family members or others say that you found to be especially helpful?

7. What, if anything, did your family members or others say that you found to be especially unhelpful?

\section{Prompted Disclosure Mechanisms}

1 Please tell me how you are or have been making sense of all that has happened. What, if anything, do you think have been the causes of events you have described here?

What or whom, if anything or anyone, do you blame for these events?

What do you think are the meanings of these events?

2 Are there better ways you can think of to view all, or some, of what has happened?

What is the "silver lining" in the cloud that has been Hurricane Katrina and its damage?

3 Can you please describe your current feelings?

4 What are actions you have thought of that you can do to make things better? 